\title{
КАЧЕСТВО И БЕЗОПАСНОСТЬ КАК ОСНОВНЫЕ ПРАВОВЫЕ КАТЕГОРИИ В УСЛОВИЯХ ФУНКЦИОНИРОВАНИЯ ОБЩЕГО РЫНКА ЛЕКАРСТВЕННЫХ ПРЕПАРАТОВ В ЕВРАЗИЙСКОМ ЭКОНОМИЧЕСКОМ СОЮЗЕ
}

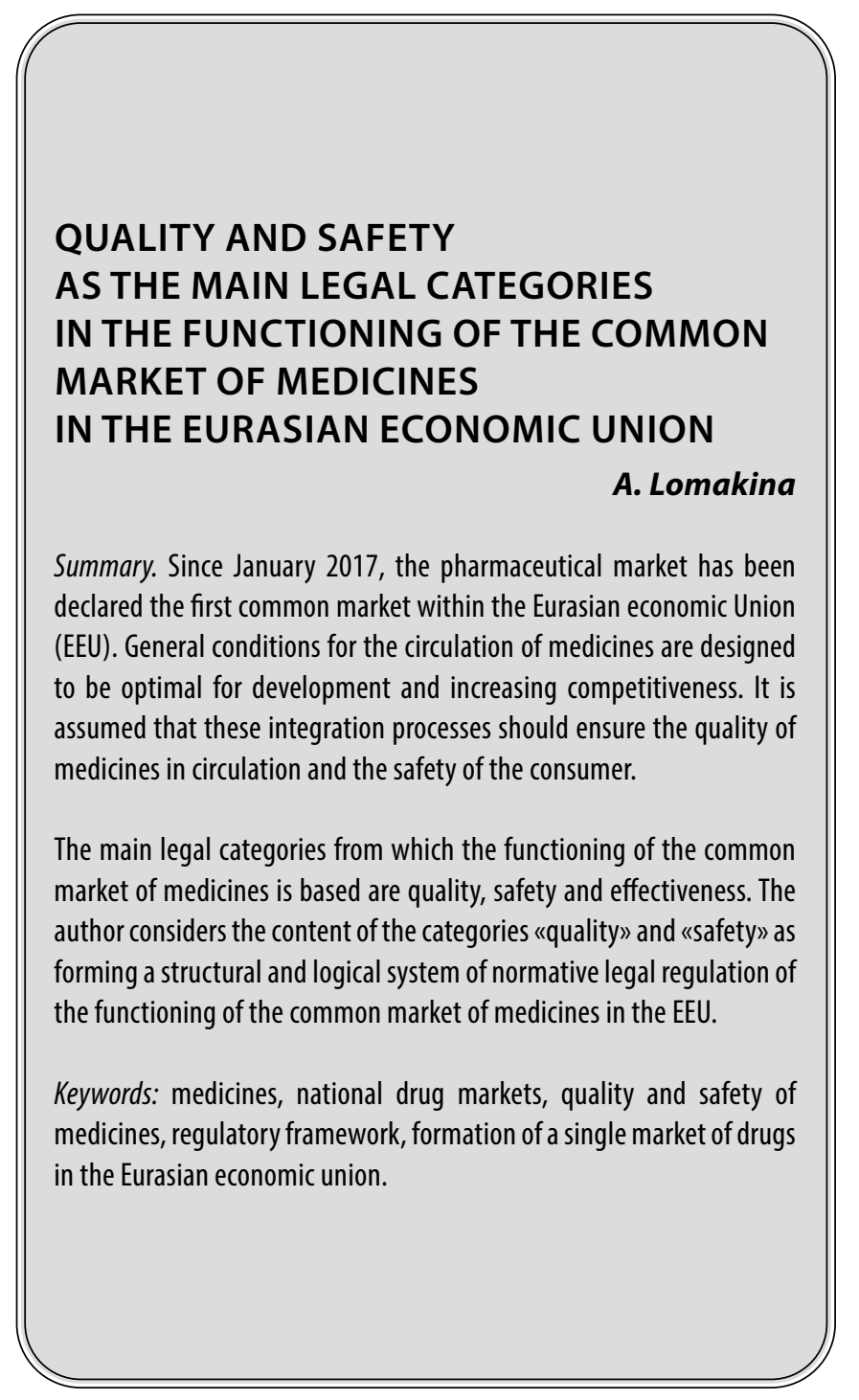

QUALITY AND SAFETY

AS THE MAIN LEGAL CATEGORIES IN THE FUNCTIONING OF THE COMMON MARKET OF MEDICINES IN THE EURASIAN ECONOMIC UNION

\section{A. Lomakina}

Summary. Since January 2017, the pharmaceutical market has been declared the first common market within the Eurasian economic Union (EEU). General conditions for the circulation of medicines are designed to be optimal for development and increasing competitiveness. It is these integration processes should ensure the quality of

The main legal categories from which the functioning of the common market of medicines is based are quality, safety and effectiveness. The author considers the content of the categories «quality» and "safety» as forming a structural and logical system of normative legal regulation of Keywords: medicines, national drug markets, quality and safety of medicines, regulatory framework, formation of a single market of drugs in the Eurasian economic union.

\author{
Ломакина Алина Амадовна \\ Московский государственный юридический \\ университет имени О.Е. Кутафина (МГЮА) \\ Alinalomakina90@yandex.ru
}

Аннотация. С января 2017 г. в рамках ЕАЭС первым общим рынком объявлен рынок фармацевтических препаратов. Общие условия обращения лекарственных средств призваны стать оптимальными для развития и повышения конкурентоспособности. Предполагается, что эти интеграционные процессы должны обеспечить качество лекарственных средств, находящихся в обращении, и безопасность потребителя. Основными правовыми категориями, на которых основывается функционирование общего рынка лекарственных препаратов, являются качество, безопасность и эффективность. Автор статьи рассматривает содержание категорий «качеств0» и «безопасность» с позиции понятий, образующих структурно-логическую систему нормативного правового регулирования функционирования общего рынка лекарственных препаратов в ЕАЭС.

Ключевые слова: лекарственные препараты, национальные рынки лекарственных средств, качество и безопасность лекарственных препаратов, нормативная правовая база, формирование единого рынка лекарственных препаратов ЕАЭС. оглашение о единых принципах и правилах обращения лекарственных средств в рамках ЕАЭС (далее - Соглашение ЕАЭС) [7], принятое в рамках Договора о Евразийском экономическом Союзе [1] было подписано в Москве 23 декабря 2014 года, и, как и другие документы, входящие в нормативную правовую базу обращения лекарственных средств в ЕАЭС, вступили в силу 6 мая 2017 года. Согласно содержанию данного Соглашения, все лекарственные препараты, уже зарегистрированные в государствах-членах ЕАЭС, должны быть приведены в соответствие с требованиями и правилами ЕАЭС до 31 декабря 2025 года, а вновь регистрируемые лекарственные препараты должны отвечать требованиям качества, безопасности и эффективности, установленным в документах ЕАЭС.

Нормативные акты, входящие в единую систему правового регулирования, обеспечивают также свое- 
образную «санацию» фармацевтического рынка ЕАЭС, заключающуюся в выведении с рынка лекарственных средств, эффективность и безопасность которых до конца не изучена и производство которых не соответствует стандартам надлежащей производственной практики.

Основными правовыми категориями, на которых основывается функционирование общего рынка лекарственных препаратов, являются качество, безопасность и эффективность, используемые во всех без исключения нормативных актах, входящих в единую систему правового регулирования общего рынка лекарственных препаратов в ЕАЭС.

Поскольку обращение лекарственных препаратов в ЕАЭС основывается на качестве и безопасности, рассмотрим содержание данных категорий.

Согласно российскому законодательному определению, данному в п. 22 ст. 4 Федерального закона «Об обращении лекарственных средств» (далее - Ф3 «Об обращении лекарственных средств») [9], качество лекарственного средства - это соответствие лекарственного средства требованиям фармакопейной статьи либо в случае ее отсутствия нормативной документации или нормативного документа. Как представляется, данное понятие, наряду с понятиями безопасности и эффективности, являются ключевой триадой в настоящем Законе.

В широком смысле слова, понятие качества представляет собой способность удовлетворения приобретателей своих потребностей за счет нужного лекарственного средства. В узком смысле, рассматриваемое понятие относится, во-первых, к эффективности и безопасности самой фармацевтической субстанции, во-вторых, к соответствию готового лекарственного средства нормативно установленным требованиям, в-третьих, к соответствию конкретного образца препарата требованиям собственной спецификации, изложенным в регистрационном досье. [6]

Понятие безопасности лекарственного средства существенно отличается от понятия качества. Под безопасностью законодатель понимать такую характеристику лекарственного средства, которая основана на сравнительном анализе его эффективности и риска причинения вреда здоровью.

Так, абсолютно все лекарственные средства связаны с определенным риском, который выражается в возможном возникновении нежелательных реакций организма (побочных действиях). Из этого следует вывод о необходимости особого контроля за безопасностью лекарственных средств как на всех стадиях его обращения, так и в последующем.

Федеральный закон от 12.04.2010 № 61-Ф3 «Об обращении лекарственных средств» является основным документом, определяющим деятельность, связанную с оборотом лекарств на территории РФ, при этом важно отметить, что данный закон отделяет лекарственные средства от продукции, стандартизуемой, выпускаемой и контролируемой по ГОСТам и другим нормативным документам. Такое разделение было всегда и в нашей стране, и во всех странах и призвано подчеркнуть необходимость обеспечения качества и безопасности лекарственных средств, как особого вида товара, представляющего собой большую социальную значимость для населения. Основой стандартизации и контроля качества лекарственных средств является фармакопея.

Развитие Государственной Фармакопеи насчитывает более чем 250 летнюю историю, что в свою очередь подчеркивает его особую значимость и актуальность. По своей структуре Государственная Фармакопея состоит из свода общих фармакопейных статей (далее ОФС) и фармакопейных статей (далее - ФС) - документов, утвержденных уполномоченным федеральным органом исполнительной власти и содержащих перечень показателей качества и методов контроля качества лекарственного средства.[9]

Российская система стандартизации лекарственных средств до недавнего времени базировалась на Государственной фармакопее, однако в условиях активно формирующегося общего рынка в рамках ЕАЭС необходимо подчеркнуть особую значимость гармонизации национальных требований государств-членов Союза с наднациональным регулированием этой сферы в целях содействия признанию глобальной фармакопейной деятельности. В настоящее время, в рамках Союза принята Фармакопея ЕАЭС, [10] являющаяся вместе с нормативно-правовыми актами ЕЭК приоритетной в применении для государств-участников Союза.

При этом, если в Фармакопее Евразийского экономического союза отсутствуют соответствующие общие фармакопейный статьи (ФС) и частные фармакопейные статьи, то ссылки могут быть приведены на фармакопею референтного государства и национальные фармакопеи государств-членов ЕАЭС, в которых лекарственный препарат регистрируется.

Поскольку в настоящее время в Фармакопею ЕАЭС пока не включены ФС на лекарственные средства, следует руководствоваться при экспертизе требованиями национальных фармакопей и Руководством по состав- 
лению нормативного документа по качеству лекарственного препарата. [11]

В частности, в отличие от других товаров, к лекарственным препаратам помимо требований обеспечения качества и безопасности применяются также требования эффективности.

Понятие «эффективность лекарственного препарата» характеризует степень положительного влияния лекарственного препарата на течение, продолжительность заболевания или его предотвращение, реабилитацию, на сохранение, предотвращение или прерывание беременности.[9]

Учитывая, что согласно статье 30 Договора о Евразийском экономическом союзе в числе основных принципов обращения лекарственных средств в рамках ЕАЭС на втором месте закреплен принцип обеспечения единства обязательных требований к качеству, эффективности и безопасности лекарственных средств, находящихся в обращении на территории Союза, в настоящее время существует необходимость последовательного анализа этих понятий в рамках государств-членов Союза, с целью их сопоставления и приведения к единому смыслу.[16]

Так, в соответствии с положениями Соглашения государства-члены при формировании общего рынка лекарственных средств в рамках Союза руководствуются едиными терминами и их определениями в соответствии с Информационным справочником понятий (терминов), применяемых в рамках ЕАЭС в сфере обращения лекарственных средств (далее - Справочник), формирование и ведение которого осуществляется Европейская экономическая комиссия.

Следует отметить, что определения качества и безопасности, данные в Справочнике, отличаются от закрепленных в российском законодательстве, однако, в наиболее общем понимании качество и безопасность (а также эффективность) гарантируют, что лекарства, вводимые пациентам и обращающиеся на едином рынке ЕАЭС, имеют соответствующее качество и обеспечивают положительный баланс пользы и риска.

В целом можно констатировать, что с новой нормативной базой общего рынка фармацевтических препаратов ЕАЭС появилась новая современная единая система правового регулирования обращения лекарственных препаратов в ЕАЭС. Такая современная единая система правового регулирования обращения лекарственных препаратов в ЕАЭС основана на принципах ее гармонизации и унификации, заключающихся в обеспечении единства обязательных требований к ка- честву, эффективности и безопасности лекарственных препаратов, которые находятся в обращении на территории ЕАЭС. Принципы единой системы правового регулирования обращения лекарственных препаратов в ЕАЭС направлены и на устранение административных барьеров при производстве и утверждении лекарственных препаратов для обращения на рынках стран ЕАЭС.

Представляется важным отметить тот факт, что требования к качеству и безопасности лекарственных препаратов начинают предъявляться еще до того, как лекарственный препарат будет доведен до пациента на этапе государственной регистрации препарата, являющейся необходимым условием для обращения лекарственного препарата на территории любой из стран, входящих в ЕАЭС. Первостепенное значение государственной регистрации лекарственного препарата заключается в выдаче разрешения на его медицинское применение. Именно на этапе государственной регистрации осуществляется проверка качества, безопасности и эффективности лекарственного препарата.

Подход, предусматривающий обязательную регистрацию лекарственных препаратов, обращающихся на едином рынке, а также особенности проверки качества и безопасности регистрируемых лекарственных препаратов, отражен в Правилах регистрации и экспертизы лекарственных средств для медицинского применения, утвержденных Решением Совета Евразийской экономической комиссии от 03.11.2016 № 78 (далее - Правила ЕАЭС № 78). Так, в Правилах ЕАЭС № 78 дается определение понятия «регистрация лекарственного препарата», согласно которому регистрация лекарственного препарата заключается в получении соответствующего разрешения на медицинское применение лекарственного препарата как на территории всего единого рынка, так и в конкретной стране ЕАЭС. Согласно Правилам ЕАЭС № 78, факт регистрации лекарственного препарата подтверждает документ единой формы, который выдается уполномоченным органом и является разрешением для его медицинского применения [2].

При подаче заявки на получение разрешения на медицинское применение заявители должны предоставить документацию, подтверждающую, что лекарственный препарат имеет соответствующее качество. Качество оценивается в соответствии с критериями, изложенными в законодательстве ЕАЭС в отношении перечня показателей качества, ссылок на аналитические методики и испытания и нормы, представляющие собой численные (количественные) пределы, диапазоны и прочие критерии для показателей качества лекарственных препаратов.

Если качественный и количественный состав лекарственного препарата не будет соответствовать 
стандартам ЕАЭС, в разрешении на регистрацию будет отказано, либо если продукт уже разрешен, разрешение будет приостановлено или отозвано. В последнем случае будут приняты все необходимые меры для обеспечения запрета поставок и изъятия лекарственного препарата с единого рынка.

Требования в отношении обеспечения безопасности и качества распространяются без исключений на все лекарственные препараты, поступающие на рынок лекарственных препаратов ЕАЭС, как через производство, так и через импорт.

В связи с влиянием практики производства и распределения на качество лекарственного препарата, включая его исходные материалы, при создании нормативного обеспечения общего рынка лекарственных препаратов отдельное внимание было уделено созданию свода правил и руководящих принципов надлежащей практики, обеспечивающих гарантии от отклонения от технических характеристик препаратов и ненадлежащей практики производства и распределения лекарственных препаратов. Такие руководяще принципы нашли отражение в Правилах надлежащей производственной практики Евразийского экономического союза, утвержденных Решением Совета Евразийской экономической комиссии от 03.11.2016 № 77 (далее - Правила ЕАЭС № 77) [6].

Обеспечение качества лекарственных препаратов начинается с этапа разработки лекарственного препарата, проведения его испытаний и заканчивается соблюдением тех свойств лекарственных препаратов, которые появляются уже после его изготовления сохранение в процессе транспортировки, сохранение в процессе хранения за счет обеспечения надлежащего температурного режима и пр.

Исходя из сказанного, можно сделать вывод о том, что «качество» как основная правовая категория функционирования общего рынка лекарственных препаратов ЕАЭС - это и соответствие критериям, методикам и прочим стандартам ЕАЭС, и совокупность технических характеристик лекарственных препаратов (численных (количественных) пределов диапазонов и критериев для показателей качества лекарственных препаратов).

Безопасность лекарственных препаратов, также как и качество лекарственных препаратов,- это важная правовая категория в условиях функционирования общего рынка лекарственных препаратов в ЕАЭС. Для новых лекарственных препаратов компании-производители обязаны доказать их безопасность с помощью результатов клинических испытаний. Данные о безопасности тщательно оцениваются соответствующими органами до выдачи разрешения на регистрацию лекарственного препарата. При этом безопасность лекарственных препаратов продолжает контролироваться и после получения регистрационного удостоверения.

Как правовая категория, категория «безопасность» применительно к лекарственным препаратам находится в неразрывной связи с категорией «качество», под которой понимается соответствие определенным требованиям и стандартам ЕАЭС и совокупность технических характеристик обозначенным и сопоставляемым характеристикам. О необходимости обеспечения безопасности лекарственных препаратов указывается в Соглашении ЕАЭС, Правилах ЕАЭС № 77, Правилах ЕАЭС № 78, а также других нормативных актах, регламентирующих функционирование общего рынка лекарственных препаратов в ЕАЭС на основе качества и безопасности лекарственных препаратов: Решении ЕЭК «Об утверждении Номенклатуры лекарственных форм» [8], Решении ЕЭК «О порядках формирования и ведения единого реестра зарегистрированных лекарственных средств Евразийского экономического союза и информационных баз данных в сфере обращения лекарственных средств» [5], Решении ЕЭК «Об утверждении требований к инструкции по медицинскому применению лекарственных препаратов и общей характеристике лекарственных препаратов для медицинского применения» [3], Решении ЕЭК «Об утверждении Требований к маркировке лекарственных средств для медицинского применения и ветеринарных лекарственных средств» [4] и пр.

В специализированной литературе предлагается понимать безопасность лекарственных препаратов как безопасность их применения в рамках оказания фармацевтической помощи [13, с. 17] и как обеспечение населения лекарственными препаратами для обеспечения здоровья и высокого качества жизни вне зависимости от обстоятельств [12, с. 4]. Однако, по мнению автора статьи, применительно к общему рынку лекарственных препаратов ЕАЭС, содержание категории «безопасность» намного шире, что обусловлено функциями безопасности как правовой категории. Согласно нормативным актам ЕАЭС, в сфере функционирования общего рынка лекарственных препаратов безопасности - это и эффективные лекарственные препараты, и качественные лекарственные препараты, и доступные лекарственные препараты, и конкурентоспособные лекарственные препараты, производство которых на территории ЕАЭС отвечает целям союза, национальным целям государств-членов и общественным целям.

Подводя итог, необходимо отметить, что смысл правовых установлений в тех или иных сферах общественных отношений имеется тогда, когда для них установлен соответствующий правовой режим. 


\section{ЛИТЕРАТУРА}

1. Договор о Евразийском экономическом союзе» (подписан в г. Астане 29.05.2014 г.) (ред. от 15.03.2018) // Официальный сайт Евразийской экономичеСкой комиссии http://www.eurasiancomission.org/. 05.06.2014 г.

2. Решение Совета Евразийской экономической комиссии от 03.11.2016 № 78 (ред. от 30.01.2020) «0 Правилах регистрации и экспертизы лекарственных средств для медицинского применения» // Официальный сайт Евразийского экономического союза http://www.eaeunion.org/, 21.11.2016.

3. Решение Совета Евразийской экономической комиссии от 03.11.2016 № 88 «0б утверждении требований к инструкции по медицинскому применению лекарственных препаратов и общей характеристике лекарственных препаратов для медицинского применения» // Официальный сайт Евразийского экономического союза http://www.eaeunion.org/, 21.11.2016.

4. Решение Совета Евразийской экономической комиссии от 03.11.2016 № 76 «0б утверждении Требований к маркировке лекарственных средств для медицинского применения и ветеринарных лекарственных средств» // Официальный сайт Евразийского экономического coюза http://www.eaeunion. org/, 21.11.2016.

5. Решение Совета Евразийской экономической комиссии от 03.11.2016 № 84 «0 порядках формирования и ведения единого реестра зарегистрированных лекарственных средств Евразийского экономического союза и информационных баз данных в сфере обращения лекарственных средств» // Официальный сайт Евразийского экономического союза http://www.eaeunion.org/, 21.11.2016.

6. Решение Совета Евразийской экономической комиссии от 03.11.2016 № 77 «0б утверждении Правил надлежащей производственной практики Евразийского экономического союза» // Официальный сайт Евразийского экономического союза http://www.eaeunion.org/, 21.11.2016.

7. Соглашение о единых принципах и правилах обращения лекарственных средств в рамках Евразийского экономического союза (Заключено в г. МоСКве 23.12.2014) // Собрание законодательства РФ. — 2016. — № 20.— Ст. 2776.

8. Решение Коллегии Евразийской экономической комиссии от 22.12.2015 № 172 «0б утверждении Номенклатуры лекарственных форм» // 0фициальный сайт Евразийского экономического союза http://www.eaeunion.org/, 30.12.2015.

9. Федеральный закон от 12.04.2010 № 61-Ф3 «06 обращении лекарственных средств»//СПС «КонсультантПлюс».

10. Решение Коллегии Евразийской экономической комиссии от 11.08 .2020 № 100 «0 Фармакопее Евразийского экономического союза» // 0фициальный сайт Евразийского экономического союза http://www.eaeunion.org/, 12.04.2018.

11. Решение Коллегии Евразийской экономической комиссии от 07.09.2018 № 151 «0б утверждении Руководства по составлению нормативного документа по качеству лекарственного препарата» // Официальный сайт Евразийского экономического союза http://www.eaeunion.org/, 23.06.2018.

12. Беляев М.А., Колоколов Г.Р., Егоров Ю.В., Хлистун Ю.В., Савина Л.В. Комментарий к ФЗ от 12.04.2010 г. № 61-Ф3 «06 обращении лекарственных средств»// СПС «КонсультантПлюс».

13. Аносов И.С. Формирование системы взаимодействия субъектов обращения лекарственных средств на основе концепции фармацевтической безопасности: Автореф. дис. ... канд. фарм. наук. - М., 2016. - С. 4.

14. Белых В.С. Гражданско-правовое обеспечение качества продукции, работ, услуг: Сб. науч. тр. / Отв. ред., сост. 0.А. Герасим0в. — Екатеринбург, 2007.

15. Маличенко В.С. Международно-правовые механизмы обеспечения безопасности обращения лекарственных средств: Автореф. дис. ... канд. юрид. наук.- М., 2015.- - С. 17.

16. Панова Альбина Сергеевна Качество товаров, работ, услуг как правовая категория // Журнал российского права. — 2010.— № 4 (160). — C. $79-85$.

17. Шевырев Д.Н. Безопасность обращения лекарственных средств: сущность и содержание // Административное право и процесс. 一 2020.—№ 2.— С. 76-79.

18. Дмитриева Г.К., Мажорина М.В. Унификация и гармонизация в международном частном праве. Вопросы теории и практики: Монография// НОРМА, ИНФРА-М — 2016 // СПС «КонсультантПлюс».

(c) Ломакина Алина Амадовна ( Alinalomakina90@yandex.ru).

Журнал «Современная наука: актуальные проблемы теории и практики» 